\title{
Study on Prolapsed Intervertebral Disc Cases Admitted in Military Hospitals
}

\author{
Ali ASMZ1 ${ }^{1}$ Zafreen $\mathrm{F}^{2}$, Wahab MA ${ }^{3}$
}

DOI: https:/ / doi.org/ 10.3329/ jafmc.v15i2.50841

\begin{abstract}
Introduction: Prolapsed intervertebral disc is a condition that can occur anywhere along the spine, but most often occurs in the lower back. It is sometimes called a bulging, protruding or ruptured disc. It is one of the most common causes of lower back pain as well as leg pain or sciatica.
\end{abstract}

Objective: To study the demographic characteristics of prolapsed lumbar intervertebral disc by age, gender, clinical presentation, levels of spinal column involvement, treatment options and post operative complications for lumbar disc prolapse.

Materials and Methods: This cross sectional study was conducted in Rangpur and Saidpur Combined Military Hospital from September 2017 to December 2018. A Total of 223 Cases was studied and data were collected by semi-structured questionnaire by face to face interview and medical documents.

Results: Most commonly affected disc spaces were $L_{5} / S_{1}(35.87 \%)$ followed by $L_{4} / L_{5}(33.18 \%)$ and $L_{4} / L_{5}, L_{5} / S_{1}(14.28 \%)$. Males were mostly affected and commonest among 30-39 years' age group (45.29\%). Chi-square test is done and result is statistically significant $(p<0.01)$. Most of the cases given conservative treatment 202(90.58\%), surgical treatment given 21(9.41\%). Mechanical backache was the most common (14.29\%) post operative complications.

Conclusion: In this study prolapsed intervertebral disc was common in the lower lumbar region at the level of $L_{4} / L_{5}$ and $L_{5} / S_{1}$.

Key-words: Backache, Sciatica, Prolapsed lumbar disc, Military personnel.

\section{Introduction}

An intervertebral disc lies between adjacent vertebrae in the vertebral column. Vertebral disc is made up of outer tough annulus fibrosus and inner gel like nucleus pulposus. The annulus fibrosus undergoes degenerative changes and inner nucleus pulposus protrudes out. Degenerative disc disease and aging ${ }^{1}$ can both lead to disc degeneration. This condition is known as disc prolapse or commonly called slipped disc. Prolapsed disc is important in our community as most of the people earn their living through stressful works, which predisposes them to spinal injuries and ultimately leading to disc prolapse. Disc prolapse is mostly postero-lateral because of the presence of posterior longitudinal ligament; however, central disc herniation does occur2. The majority (95\%) of disc prolapses occurs in lumbar region ${ }^{3}$ at the level of $L_{4} / L_{5}$ or $L_{5} / S_{1}$. Professionals sitting for prolonged period in the offices, smoking, weight lifting, trauma and driving are all at a greater risk for disc prolapse. Age is related to wear and tear of the disc4. According to most authors, degenerative diseases are more important causes of disc prolapse than trauma ${ }^{5}$. Professional athletes are prone to disc injuries ${ }^{6,7}$. Backache, due to pressure on ligaments and sciatica, due to compression of nerves, mostly forms the initial presentation of the disc prolapse. Compression of other nerve roots leads to weakness of muscles, numbness in the limbs, paresthesias and urinary retention due to compression of cauda equina nerves. The life time incidence of sciatica ${ }^{8}$ has been reported from $13-40 \%$ in the general population. Disc prolapsed is genetically driven- twin studies indicate that at least $60 \%$ of the variance can be explained on genetic grounds and not by the commonly assumed environmental factors (work, trauma, exposure to excessive driving, smoking and so on). Current guidelines indicate that radicular pain should improve within six to eight weeks with conservative management. Surgery should be performed before eight weeks only in patients with progressive neurological deficit, which can be detected by magnetic resonance imaging.

At the level of prolapse paresthesia, muscle weakness and decreased reflexes might be noted. With the impairment of $L 5$ nerve roots; there is loss of sensation on the dorsal side of the foot and lateral side of the leg and weakness in the extension of big toe. Patients might have difficulty in walking on the heel. The impairment of $S_{1}$ nerve roots, leads weakness in ankle jerk reflex, weakness in plantar flexion, weakness in the eversion of the foot and loss of sensation on the lateral and planter aspect of the foot. Due to compression of cauda equina nerves, findings may include loss of sensation in the lower back and urinary retention. The differential diagnosis for disc prolapse includes tuberculosis, spinal stenosis, vertebral abscess, ankylosing spondylitis, vertebral hematomas, vertebral tumors, nerve tumors. To study the demographic characteristics of prolapsed lumbar intervertebral disc by age, gender, clinical presentation, levels of spinal column involvement, treatment options and post-operative complications for lumbar disc prolapse.

\section{Materials and Methods}

This cross sectional study was carried out in the Orthopedic Surgery Department of Rangpur and Saidpur combined military Hospitals from September 2017 to December 2018. A total of 223 prolapsed lumbar disc patients were studied. Detail history of the patient was taken during follow up in which patients were asked about relieve of preoperative symptoms and development of any new symptoms. In each follow up complete neurological examination was done. The patient with poor motor function and myelopathy were subjected to surgery which was done at Combined Military Hospital Dhaka. Data were processed and analyzed by computer software SPSS version 20 and expressed in frequency and percentage. 


\section{Results}

Out of 223 patients' male were $175(78.47 \%)$ and female $48(21.52 \%)$. Mean age of the patients was $37.68 \pm 5.64$ years and ranged from 20 to 59 years. The lumbar disc prolapse was common (45.29\%) in the patients of 30-39 years. The level of disc prolapse was confirmed on MRI scan of vertebral column. Most Commonly affected disc spaces were $L_{5} / S_{1}(35.87 \%), L_{4} / L_{5}(33.18 \%)$ and both $\mathrm{L}_{4} / \mathrm{L}_{5} \mathrm{~L}_{5} / \mathrm{S}_{1}(19.28 \%)$ (Table-I). The most common symptoms seen in the patients of lumbar disc prolapse was backache (31.39\%) followed by sciatica (right side sciatica $22.87 \%$, left side sciatica $25.11 \%$ and bilateral sciatica $13.45 \%$ ) and neurogenic claudication $5.82 \%$. Most of the patients $202(90.58 \%)$ were conservatively treated and rest of the patients $21(9.41 \%)$ underwent surgery ((Table-II). Complications of surgeries noted in this study were recurrence of symptoms and mechanical backache (14.29\%) (Table-III).

Table-l: Age, level of disc prolapses and sex distribution of respondents $(n=223)$

\begin{tabular}{|c|c|c|c|c|}
\hline \multirow{2}{*}{\multicolumn{2}{|c|}{ Characteristics }} & \multicolumn{2}{|c|}{ Sex } & \multirow{3}{*}{$\begin{array}{c}\begin{array}{c}\text { Total } \\
\mathrm{n}(\%)\end{array} \\
38(17.07)\end{array}$} \\
\hline & & \multirow{2}{*}{$\begin{array}{c}\begin{array}{c}\text { Male } \\
\mathrm{n}(\%)\end{array} \\
34(19.42)\end{array}$} & \multirow{2}{*}{$\begin{array}{c}\text { Female } \\
\mathrm{n}(\%)\end{array}$} & \\
\hline \multirow{5}{*}{$\begin{array}{l}\text { Age } \\
\text { group in } \\
\text { years }\end{array}$} & $20-29$ & & & \\
\hline & $30-39$ & $86(49.14)$ & $15(08.57)$ & $101(45.29)$ \\
\hline & $40-49$ & $40(22.85)$ & $19(10.85)$ & $59(26.45)$ \\
\hline & $50-59$ & $15(8.57)$ & $10(05.71)$ & 25 (11.21) \\
\hline & Total & $175(78.47)$ & $48(21.52)$ & $223(100)$ \\
\hline \multirow{8}{*}{$\begin{array}{l}\text { Level of } \\
\text { disc } \\
\text { prolapse }\end{array}$} & $\mathrm{L}_{5} / \mathrm{S}_{1}$ & $66(37.71)$ & $14(29.16)$ & $80(35.87)$ \\
\hline & $\mathrm{L}_{4} / \mathrm{L}_{5}$ & $58(33.14)$ & $16(33.33)$ & 74 (33.18) \\
\hline & $\mathrm{L}_{2} / \mathrm{L}_{3}$ & $02(1.14)$ & $01(2.08)$ & 03 (1.34) \\
\hline & $\mathrm{L}_{3} / \mathrm{L}_{4}$ & $04(2.28)$ & $01(02.08)$ & 05 (2.24) \\
\hline & $\begin{array}{l}\mathrm{L}_{3} / \mathrm{L}_{4} \\
\mathrm{~L}_{4} / \mathrm{L}_{5}\end{array}$ & $08(4.57)$ & $03(06.25)$ & $11(4.93)$ \\
\hline & $\begin{array}{l}\mathrm{L}_{4} / \mathrm{L}_{5} \\
\mathrm{~L}_{5} / \mathrm{S}_{1}\end{array}$ & 31 (17.71) & $12(25.00)$ & $43(19.28)$ \\
\hline & $\begin{array}{l}\mathrm{L}_{3} / \mathrm{L}_{4}, \\
\mathrm{~L}_{4} / \mathrm{L}_{5} \\
\mathrm{~L}_{5} / \mathrm{S}_{1}\end{array}$ & 06 (3.42) & $01(02.08)$ & 07 (3.13) \\
\hline & Total & $175(78.47)$ & $48(21.52)$ & $223(100)$ \\
\hline
\end{tabular}

Table-II: Distribution of PID patients by clinical signs and symptoms $(n=223)$

\begin{tabular}{|l|l|l|l|}
\hline \multicolumn{2}{|c|}{ Characteristics } & Frequency & Percentage \\
\hline \multirow{4}{*}{$\begin{array}{l}\text { Clinical } \\
\text { signs and } \\
\text { symptoms }\end{array}$} & Backache & 70 & 31.39 \\
\cline { 2 - 4 } & $\begin{array}{l}\text { Rt Side } \\
\text { Sciatica }\end{array}$ & 51 & 22.87 \\
\cline { 2 - 4 } & Lt Side Sciatica & 56 & 25.11 \\
\cline { 2 - 4 } & $\begin{array}{l}\text { Bilateral } \\
\text { Sciatica }\end{array}$ & 30 & 13.45 \\
\cline { 2 - 4 } & $\begin{array}{l}\text { Neurogenic } \\
\text { claudication }\end{array}$ & 13 & 5.82 \\
\cline { 2 - 4 } & Foot drop & 03 & 1.34 \\
\cline { 2 - 4 } & Total & 223 & 100 \\
\hline \multirow{2}{*}{$\begin{array}{l}\text { Treatment } \\
\text { modalities }\end{array}$} & Conservative & 202 & 90.58 \\
\cline { 2 - 4 } & Surgical & 21 & 9.41 \\
\cline { 2 - 4 } & Total: & 223 & 100 \\
\hline
\end{tabular}

Table-III: Complications of surgery for lumbar PID $(n=21)$

\begin{tabular}{|l|c|c|}
\hline \multicolumn{1}{|c|}{ Complications } & Frequency & Percentage \\
\hline Recurrence of symptoms & 01 & 4.76 \\
\hline Mechanical backache & 03 & 14.29 \\
\hline No complications & 17 & 80.95 \\
\hline
\end{tabular}

\section{Discussion}

Out of total patients 'males were $175(78.47 \%)$ and females were 48 (21.52\%). The frequencies of males were higher than female. In this study mean age of the patients was $37.68+/-5.64$ years and ranged from 20 to 59 years. The increased frequency of males was also seen in other studies. In the study of Prasad $\mathrm{R}^{9}, 65.6 \%$ were males and $34.4 \%$ were females and other Study by Moein $\mathrm{H}^{10}$ males constituted $71 \%$ of the patients and females constituted $29 \%$. Lumbar disc prolapse in Kenya by Ongeti KW11 was more common in females. Lumbar disc prolapse was found to be common in age group B (30-39 years) $45.29 \%$ and age group C (40-49 years) $26.45 \%$. Similarly considering gender, lumbar disc prolapse was common in males in age group B (30-39 years) $49.14 \%$ and in females it was common in age group C (40-49 years) $10.85 \%$. Study by $\mathrm{R}$ Prasad ${ }^{9}$ showed that age of presentation for prolapsed disc in male was $21-30$ years (31.88\%) and in female was $31-40$ years (48.83\%). Study by Prasad $\mathrm{R}^{9}$ showed that prolapsed disc was common in younger ages as compare to this study. In this study most commonly affected disc spaces were at $\mathrm{L}^{5} \mathrm{~S}^{1}$ level (35.87\%), $L^{4} L^{5}$ level $(33.18 \%)$ and $19.28 \%$ of patients had disc involvement at two levels $\left(L_{4} / L_{5}\right.$ and $\left(L_{5} / S_{1}\right)$. Study by R Prasad ${ }^{9}$ disc prolapse was seen to be most common at the level of $L_{4} / L_{5}(34.4 \%)$, which was then followed by the disc proapse at $L_{5} / S_{1}$ level $(26.7 \%)$.

Study by Moein $\mathrm{H}^{10} 61 \%$ of patients had disc prolapsed at $\mathrm{L}_{4}-\mathrm{L}_{5}$ Level and $32 \%$ of patients had disc herniation at two levels. This means disc prolapsedis common at the level of $L_{4} / L_{5}$ and $L_{5} / S_{1}$ intervertebral disc space in this study as well as other studies9.10. There are two main types of treatment for lumbar disc prolapsed, Conservative and Surgery ${ }^{12}$. In this study, 90.58\% Patients were conservatively treated while rest of the patients 21 (9.41\%) underwent surgery. Excision of disc provides rapid relief of sciatica and lower back pain ${ }^{13}$. The relative frequency of different surgeries performed given in the Table-V. The result of this study comparable to the study by Siddiq $\mathrm{M}^{14}$ et al for operative treatment of disc prolapse (75\%)were male and $25 \%$ were female in this study ${ }^{14}$, while in our study $78.47 \%$ were males and $21.52 \%$ were female. Studies by Siddiq $\mathrm{M}^{14}$, most of the affected patients were in $4^{\text {th }}$ and $5^{\text {th }}$ decade of life. In this study ${ }^{14}$ most commonly affected disc space was $L_{4} / L_{5}(56.25 \%)$ while in our study $L_{5} / S 1(35.87 \%)$ was commonly affected. The complications noted the study ${ }^{14}$ were dural tear $6.25 \%$, discitis $3.12 \%$, wound infection $2.12 \%$. In this study complications was mechanical backache (14.29\%) and recurrence of symptoms $7 \%$. Most patients $80.95 \%$ didn't have any complication after surgery.

\section{Conclusion}

This study showed that lumbar PID is common in the age group of 30-39 years. It is most commonly occurred at the level of $L_{4}-L_{5}$ and L5-S1. Common clinical presentation is backache and sciatica. Most of the patients are treated conservatively and others underwent surgery. 


\section{References}

1. Del Grande F, Maus TP, Grarino JA. Imaging the intervertebral disk: age-related changes, herniations and radicular pain. Radiol Clin North Am 2012; 50(4):629-49.

2. Gerald L, Burke, Backache: From Occiput to Coccy Mac Donald Publishing, 2008.

3. Moor KL, AGUR amr. Essential clinical anatomy. $3^{\text {rd }}$ ed. Philadelphia, PA Lippincott Williams \$ Wilking, 2007:692.

4. Urban J,Roberts S. Degeneration of the intervertebral disc. Arthritis Research and Therapy 2003; 5(3):120-130.

5. Herkowitze HN, Rothman RH, Simoine FA, editors. RothmanSimeone, the spine. Philadelphia. Sauders Elsevier, 2006:2.

6. Hus Wk. Lumbar and Cervical Disc Herniations in NFL Players: Return to Action. Orthopedics 2012; 35(1):43-9.

7. Earhart JS, Roberts D, Roc $G$ et al. Effects of lumbar disk herniation on the careers of professional baseball players Orthopedics 2012; 35(1):43-9.

8. Stafford MA, Peng P, Hill DA. Sciatica: A review of history, epidemiology, pathogenesis and the role of epidural steroid injection in management. Br J Anaesth 2007; 99(4):461-73.
9. Prasad $\mathrm{R}$, Hoda $\mathrm{M}$, Dhakal $\mathrm{M}$ et al. Epidemiological characteristics of lumbar disc prolase in a tertiary care hospital. Internet J Neurosurg 2006; 3(1).

10. Moein $\mathrm{H}$. A retrospective study of 1250 cases of lumbar disc hemiation operated upon at two hospitals of Isfahan University of Medical Sciences. J Kerman Univ Med Sci 1995; 3(1):1-6.

11. Ongeti KW, Ogeng'o J, Gakuu LN et al. Prolapsed Intervertebral Disc in and African Population: Kenyan Experience. East Afr Orthop J 2012; 6(1):12-5.

12. Zeng YF. Clinical observation on treatment of 67 cases with lumbar intervertebral disc hemiation with abdomen acupuncture. J Acupunct Tuina Sci 2008; 6:42-5.

13. Toyone T, Tanaka T, Kato D, Kaneyama R. Low-back pain following surgery for lumbar disc herniation J Bone Joint Surg Am 2004;86-A (5):893-6.

14. Siddiq M, Ali N, Jan WA et al. Surgical Management of Lumbar Disc herniation by Standard Laminectomy in a Periphery Hospital; An experience with 64 patients. J Postgrad Med Inst Peshawar-Pak 2011; 17(1). 